\title{
O método em Filologia
}

José Pereira da Silva ${ }^{1}$

Resumo: O artigo faz um excurso crítico sobre os estudos filológicos, abordando a questão do método, indissociável da história da linguística românica.

Palavras-chave: Filologia. Método. Crítica textual. Ecdótica.

\section{Introdução}

Como sintetiza Benedek Elemér Vidos, "o método e a história da linguística românica não se podem separar", "e se alguém deseja ter uma ideia clara da origem e desenvolvimento desta ciência, é necessário que a veja à luz dos vários períodos históricos em que operavam aqueles que a ela se dedicaram" (VIDOS, 1996, p. 29). É necessário, entretanto, que distingamos uma divisão muito séria nos estudos filológicos, isto é, os estudos filológicos em sentido amplo, que incluem, conforme José Leite de Vasconcellos resume (VASCONCELLOS, 1966, p. 8):

História da língua (glotologia, glótica, linguística e seus ramos), com a estilística e a metrificação;

História literária:

1) História da literatura (em sentido amplo), com a crítica literária;

2) Bibliografia.

O mesmo José Leite de Vasconcellos, considerando a filologia em seu aspecto prático e, naturalmente, mais restrito, ensina: "Faz-se aplicação prática da filologia, quando se edita criticamente, e se comenta, um texto" (VASCONCELLOS, 1966, p. 8).

Deste modo, podemos organizar este trabalho em duas partes principais: a primeira, tratando da filologia em seu sentido amplo, de modo que possamos levar em consideração o que Vasconcellos já apontara sobre suas aulas: "Nas minhas preleções, entendo de ordinário por filologia portuguesa o estudo da nossa língua em toda a sua amplitude, no tempo e no espaço, e, acessoriamente, o da literatura, olhada, sobretudo como documento formal da mesma língua" (VASCONCELLOS, 1996, p. 9).

\footnotetext{
${ }^{1}$ José Pereira da Silva é filólogo, professor aposentado da Universidade do Estado do Rio de Janeiro e foi editor da Revista Soletras em toda sua fase de publicação impressa. Email: pereira@ filologia.org.br.
} 
Adepta das ideias filológicas de Vasconcellos, Carolina Michaëllis de Vasconcelos desenvolve dois longos capítulos em suas Lições de filologia portuguesa, para ensinar o sentido do termo "filologia" e a história da ciência filológica (Cf. VASCONCELOS, s/d, p. 125-145). E, para registrar o seu nascimento na Grécia antiga, transcreve-se um longo fragmento de seu livro (VASCONCELOS, s/d, p. 137-138):

\begin{abstract}
Quando a assombrosa força inventiva do gênio helênico, que criara quinhentos anos antes de Cristo todas as ciências e artes, a prosa artística e todos os gêneros poéticos cultivados nas literaturas [...], quando essa assombrosa força inventiva ia declinando, os descendentes começaram a sistematizar as ciências (como Aristóteles) e a alimentar-se e inspirar-se nos tesouros nacionais dispersos pelo país fora ${ }^{2}$.

Colecionaram, trasladaram, interpretaram e restauraram então os monumentos antigos - deturpados ao passarem tradicionalmente, ou em sucessivas cópias, de geração em geração, de dialeto ${ }^{3}$ de uma paisagem no dialeto de outra paisagem.

Intérpretes naturais dos autores eram os que costumavam ensinar língua e literatura pátria: os gramáticos e os pedagogos.

Principiando com comentários meramente vocabulares, métricos e etimológicos, passaram breve da crítica dos textos à hermenêutica, isto é, à explicação de ideias, fatos, alusões e coisas reais. [...]

Para bem comentar qualquer autor arcaico, em toda a amplitude do termo proporcionando aos leitores o conhecimento da vida íntima da nação no tempo dele, sobretudo para bem explicar cabalmente Homero, o mais antigo, mais lido e famigerado dos autores helênicos - para tratar condignamente as lendas históricas e mitológicas e toda a cultura de que há manifestações na Ilíada e Odisseia, era preciso um saber enciclopédico. Os fundamentos (é bom acentuá-lo sempre de novo) eram, contudo, estudos aprofundados da linguagem: do valor primitivo dos vocábulos, da fonologia, da morfologia, dos dialetos variegados, assim como das evoluções da linguagem literária da Grécia e das colônias.
\end{abstract}

Fica evidente, naturalmente, que a filologia já não pretende ser a ciência que descreve os sistemas linguísticos, hoje de atribuição da linguística, mas não pode abrir mão de estudálos para efetuar com a maior precisão e simplicidade possível a sua interpretação, a sua explicação ou ensino e a preservação da memória cultural do povo que utilizou as línguas que já não se usam efetivamente, mas permanecem nos textos antigos.

\footnotetext{
${ }^{2}$ Tratando da edição crítica de textos, Erich Auerbach (1972, p. 11) escreve: “A necessidade de constituir textos autênticos se faz sentir quando um povo de alta civilização toma consciência dessa civilização e deseja preservar dos estragos do tempo as obras que lhe constituem o patrimônio espiritual; salvá-las não somente do olvido como também das alterações, mutilações e adições que o uso popular ou o desleixo dos copistas nelas introduzem necessariamente".

${ }^{3}$ Parece-me importante registrar o que escreveu com propriedade Lluís V. Aracil (2004, p. 15): “A língua, com maiúscula ou minúscula, é a língua nacional”. Assim, quando se fala, por exemplo, de "Acordo Ortográfico da Língua Portuguesa", está-se falando da língua oficial dos países que a utilizam como tal. Todas as outras variantes dessa língua nacional costumam ser chamadas de dialetos, apesar dos protestos de alguns.
} 
Apesar de não ser a língua o objetivo do estudo filológico, é a matéria na qual, em sua forma escrita (hoje pode ser preservada de outras formas também), se manifesta a cultura dos povos, cuja preservação é da responsabilidade dos filólogos (e de outros especialistas também, naturalmente).

Não é possível buscar um objetivo sem compreender bem o objeto no qual ele se manifesta e se preserva. E, no caso da filologia, é nos textos das diversas línguas que está o objeto de seu estudo.

Depois de tratar da crítica textual como "o trabalho filológico", Bruno Fregni Bassetto inicia o capítulo sobre os métodos da filologia românica de seus Elementos de filologia românica, com as seguintes palavras:

\begin{abstract}
Dentre os vários métodos utilizados em filologia românica, uns são mais adequados e, por isso, mais produtivos, enquanto outros, emprestados de ciências afins, trazem apenas alguma contribuição para um conhecimento maior dos conteúdos da romanística. Para uma visão mais completa de determinados problemas, frequentemente é preciso aplicar mais de um método e confrontar os resultados obtidos (BASSETO, 2001, p. 63).
\end{abstract}

\title{
1. Os métodos da filologia em sentido amplo
}

O professor Bruno é muito feliz neste parágrafo, em que sintetiza de forma clara uma conclusão natural de quem estuda atentamente os métodos filológicos aplicados às línguas românicas, nos seguintes termos:

\begin{abstract}
A linguagem é, inegavelmente, uma herança social, cuja história se estende por séculos. Uma visão completa, um conhecimento detalhado de seu mecanismo, de sua estrutura, de sua semântica e até de sua ortografia só podem ser obtidos através da pesquisa diacrônica. Os métodos, expostos acima em suas linhas essenciais, não deixam dúvida de que a filologia românica se desenvolveu com o método histórico-comparativo, adotado com mais êxito aqui do que no campo para o qual havia sido criado. As possíveis deficiências desse método foram sendo corrigidas depois pela geografia linguística e pelos outros métodos derivados, como a onomasiologia, Wörter und Sachen, linguística espacial etc. Enquanto o método históricocomparativo procura as ligações entre o "terminus a quo" e o "terminus ad quem", o latim vulgar e as línguas românicas respectivamente, os outros métodos têm como objeto especificamente o "terminus ad quem", pois investigam sincronicamente aspectos atuais dessas mesmas línguas, cujas explicações, porém, devem ser buscadas diacronicamente (BASSETTO, 2001, p. 85).
\end{abstract}


A conclusão do professor Bruno está bem fundamentada e é inquestionável. Naturalmente, para os filólogos e linguistas que se dedicam a línguas não românicas, nem sempre o método histórico-comparativo será tão produtivo, motivo pelo qual a filologia e linguística românica vem sendo considerada como a praeceptrix linguisticae (mãe da linguística) porque somente as línguas românicas possuem documentos históricos com os quais possam comprovar suas hipóteses.

\subsection{Método histórico-comparativo}

O método histórico-comparativo foi criado por Franz Bopp (1791-1867) e Jacob Grimm (1785-1863) no início do século XIX e, imediatamente, aplicado por Friedrich Diez (17941876) na elaboração de sua Gramática das línguas românicas e de seu Dicionário etimológico das línguas românicas, que foram a base da criação da filologia românica e da linguística românica.

$\mathrm{Na}$ verdade, os fundamentos da linguística comparada foram preparados por Franz Bopp com a publicação de sua Gramática comparativa, com a qual conseguiu refutar a ideia equivocada defendida por Friedrich Schlegel (1772-1829) de que o grego e o latim eram provenientes do sânscrito. Mas os fundamentos da linguística histórica só foram estabelecidos concretamente por Jacob Grimm, com a publicação de sua Gramática germânica. Apesar de contemporâneas em sua efetiva formulação científica, a linguística histórica é proveniente da linguística comparativa (Cf. VIDOS, 1996, p. 33-34).

Segundo Vidos (1996, p. 34), para se consagrar inquestionavelmente como o criador da filologia e linguística românica, Diez não fez mais que aplicar às línguas românicas, em sua Gramática, a gramática e o método de Jacob Grimm. E sua contribuição foi tão fundamental que até hoje sua gramática e seu dicionário ainda têm utilidade, apesar dos avanços nesses estudos.

O método histórico-comparativo, como está evidente em seu próprio nome, é a fusão do método histórico com o comparativo. Ou seja, o método histórico procura explicar as causas e/ou consequências dos fatos linguísticos através da observação de dois ou mais estágios cronológicos de uma língua comprovados em alguma forma de documento (normalmente um texto escrito). O método comparativo, já imanente também no método histórico, é utilizado também para cotejar estágios de evolução de diversas línguas ou dialetos nas diferentes regiões em que são faladas ou documentadas. Fazendo-se essas comparações com um número exaustivo de casos semelhantes, estabelecem-se normas, regras ou "leis" que possibilitam a 
reconstituição de formas linguísticas não documentadas para explicar a etimologia de muitas palavras.

Trata-se, portanto, do método básico da linguística românica, a partir do qual todo o seu progresso se deu, pois os outros métodos e movimentos subsequentes surgiram para corrigir algum aspecto do método histórico-comparativo. Com isto, foi se aperfeiçoando e transformando no mais importante método aplicável aos estudos diacrônicos da linguística românica.

A busca do sentido original de uma palavra, ou o sentido mais remoto possível, é uma tarefa que tem preocupado o homem desde os mais antigos estudos linguísticos de que se tem notícia. Numerosos estudos etimológicos têm sido elaborados; uns, mais completos; outros, menos; mas nenhum deles pôde ser construído sem o método histórico-comparativo, apesar de serem antigos de milênios.

No seu recente livro, Etimologia, Mário Eduardo Viaro (2011) estabelece as bases para um novo impulso nos estudos etimológicos, de modo a torná-los mais conceituados cientificamente.

Os estudos de gramática histórica das línguas românicas, seja isoladamente, ou em seu conjunto só podem ser feitos através do método histórico-comparativo e, felizmente, com muito mais sucesso do que em quaisquer outras línguas, pelos motivos acima relacionados.

Resumindo, destacamos que o método histórico-comparativo aplicado ao português consiste em relacionar os estágios passados de cada fonema, vocábulo ou frase e identificar a relação histórica de causa e consequência identificada na sua evolução cronológica.

Em alguns casos, a comparação com a evolução ocorrida nas outras línguas românicas complementa a método, quando se pretende buscar a origem de um fonema, de uma palavra ou de uma construção, pois seria inviável que fatos linguísticos similares ocorressem em diversas línguas simultaneamente por mero acaso.

Vejamos, a seguir, uma síntese de outros métodos que surgiram para aperfeiçoar o método histórico-comparativo, criticando sempre algum ponto em que este era menos eficiente.

\subsection{Método idealista}

A partir da percepção de Wilhelm von Humbold (1767-1835), de que a língua é o produto do espírito humano, "que se manifesta na língua como na sociedade, nas ciências e nas artes", os idealistas chegaram à conclusão de que ela "não pode ser considerada como um 
produto, mas como uma criação" (Apud VIDOS, 1996, p. 94). Sendo assim, segundo Humbold, a língua não reproduz as coisas tais como são na realidade, mas tais como os falantes as idealizam. Essa forma interior da linguagem representa a realidade que os circunda, mas só se manifesta externamente através da fonética, da morfossintaxe etc.

Segundo Vidos (1996, p. 95), Karl Vossler (1872-1949) pretendeu demonstrar que "as mudanças fonéticas dependem do acento e do ritmo e que estes, por sua vez, dependem do estado de espírito de quem fala". Por isto, conclui que "toda expressão linguística é uma criação do espírito" e que "a história das formas de expressão linguística só pode ser a história das criações do espírito; noutras palavras, história do espírito, história da cultura" (VIDOS, 1996, p. 101-102).

Auxiliados pelo mesmo autor (VIDOS, 1996, p. 101-102), ainda podemos concluir que

Apesar de todas as suas deficiências, o método idealista tem o grande mérito de ter fixado a atenção sobre quanto há de individual e de criativo na vida da linguagem. Cooperou eficazmente para fazer vir à luz os fatores artísticos, estéticos e espirituais na língua. Indicando a estética como a "rainha absoluta da filologia", o idealismo fez justiça à estilística, até então descuidada, na qual o caráter estético, as possibilidades individuais de expressão da língua aparecem mais claramente e, com ela, também a sintaxe. Desta maneira, o idealismo reagiu saudavelmente contra o excesso de fonética por parte do método histórico-comparativo, contra o "positivismo fonetizante", que muito positivistamente queria considerar a analogia na fonética como um fator de perturbação e não como uma força diretriz de origem espiritual.

\subsection{Método da geografia linguística}

Na segunda metade do século XIX, Graziadio Isaia Ascoli (1829-1907) criou a dialetologia italiana, devendo ser considerado o fundador da dialetologia românica. Seus famosos Ensaios Ladinos constituíram o primeiro volume do periódico Archivio Glolologico Italiano (1873), criado para publicar seus próprios trabalhos, entre os quais se destaca ainda, no $8^{\circ}$ número, o artigo “A Itália dialetal”, a partir da página 98.

Segundo Iordan (1982, p. 34), os estudos dialetais podem ser muito úteis para o estudos linguísticos em geral, porque

A observação direta dos fenômenos linguísticos, aplicada à língua viva, fornece-nos dados bastante seguros sobre o modo como se podem ter consumado todas as transformações nas fases anteriores de qualquer idioma, enquanto o inverso nem sempre é verdadeiro, isto é, o estudo dos estados antigos da língua não nos ajudaria a compreender os atuais. 
Mais adiante, tratando da geografia linguística, escreveu ainda Iordan:

\begin{abstract}
Quando os linguistas se lembraram de apresentar os dados da investigação sob a forma de atlas, deu-se um passo em frente; estes se denominaram atlas linguísticos, dado que tinham objetivos diversos dos atlas geográficos. Esta ideia surgiu quase espontaneamente, quando os especialistas sentiram a súbita necessidade de estudar vários dialetos. Para compará-los, sem dificuldade, era imprescindível poder abarcar com uma vista de olhos qualquer particularidade fonética ou morfológica em todos os dialetos duma dada área. O meio que permitiu a realização deste objetivo foi a anotação, numa carta do território estudado, dos fenômenos em questão. Em vez de ser preciso compulsar algumas dúzias de glossários - e partindo do princípio que os temos à nossa disposição -, para observar como se transformou esta ou aquela forma fonética ou gramatical em dez dialetos a estudar, basta examinar a carta respectiva (IORDAN, 1982, p. 199).
\end{abstract}

Abandonando quase absolutamente a pesquisa bibliográfica, Jules Gilliéron (18541926) inovou a metodologia da linguística ao priorizar a pesquisa de campo. Com isto, demonstrou que

[...] operou crucialmente na formação dos dialetos românicos a criatividade dos falantes, particularmente ativa toda vez que se tornava necessário desfazer colisões homonímicas e salvar palavras foneticamente pouco consistentes, ou toda vez que a etimologia popular alterou a forma de uma palavra para relacioná-la a algum paradigma conhecido (ILARI, 1992, p. 26).

Do início do século XX até hoje, a geografia linguística evoluiu muito, principalmente porque os equipamentos para coleta de dados sofreram enorme progresso, de modo que atualmente é possível transcrever o som e a imagem com precisão quase absoluta e disponibilizá-los em arquivos virtuais para consulta direta e imediata pelo usuário, que pode ver e ouvir a manifestação dialetal dos informantes, onde estiver e a qualquer momento.

No Brasil, o Projeto Atlas Linguístico do Brasil vem coordenando uma grande quantidade de pesquisas regionais para se produzir um Atlas linguístico resultante da fusão de numerosos atlas estaduais ou regionais, dos quais se publicou no ano passado o Atlas Linguístico do Estado do Ceará, em dois volumes, depois de vários outros já publicados anteriormente.

Além dos diversos projetos regionais brasileiros que integram o Atlas Linguístico do Brasil, há pelo menos um projeto plurilinguístico que envolve o português do Brasil, o espanhol e o guarani (THUN et alii, 2009), do qual já foi publicado, na Alemanha, um 
volume de grande interesse para nós, como parte do projeto "Dialectologia pluridimensionalis Romanica".

\subsection{Método de "palavras e coisas"}

Bruno Bassetto (2001, p. 74-76) sintetizou com muita propriedade as informações essenciais sobre este método, que resumiremos ainda mais aqui.

Sem abandonar o aspecto fonético da língua, a geografia linguística aprofundou as pesquisas no âmbito da semântica. Descreveu-se, então, a natureza, as medidas, as formas, os usos etc. das coisas, considerando-se que isto facilitaria a fixação da origem e da história das palavras com as quais elas estão relacionadas.

Cientes de que as coisas precedem as suas denominações, os filólogos que primeiramente aplicaram o método consideravam que há sempre uma relação muito estreita entre as coisas e suas denominações. Assim, pelo conhecimento profundo da "coisa", chegase ao étimo da palavra que a designa.

Enfim, tornando mais objetivos os estudos filológicos e valorizando devidamente a semântica, o método de "Palavras e Coisas" ampliou as possibilidades do método históricocomparativo, "buscando o que há de vivo e não sujeito às cegas leis na linguagem; buscando estabelecer a etimologia e até a biografia das palavras" (BASSETTO, 2001, p. 76).

\subsection{Método onomasiológico}

Investigando os aspectos vivos e as forças criadoras da linguagem, a onomasiologia estuda as denominações das "coisas" e identifica, na língua do povo, a cultura, os costumes, as ocupações, o instrumental, as crenças e crendices, a moradia, toda a relação do homem com o ambiente em que vive. Possibilita, inclusive, "caracterizar as atividades de uma região e situá-la no tempo", como se pode perceber, comparando o vocabulário relativo a transporte de uma região servida de rios navegáveis como o Pará ou o Amazonas, com o correspondente vocabulário de região desprovida de tais rios, como é boa parte dos estados do Nordeste.

A onomasiologia, seguindo o caminho inverso da etimologia, é muito eficiente no estudo da história e da biografia das palavras, visto que a etimologia, segundo o professor Bruno Fregni Bassetto, 
[...] toma o significante para chegar aos significados, enquanto aquela procura dar a história da palavra, desde a época mais antiga até chegar aos nossos dias, explicando, ou pelo menos tentando explicar, as diversas influências sofridas, os cruzamentos semânticos, sua vitalidade e frequência de uso etc. (BASSETTO, 2001, p. 78).

\subsection{Método neolinguístico ou espacial}

Apesar de combater a rigidez das "leis fonéticas" dos neogramáticos, a linguística espacial estabelece novas "leis", com o nome de "normas areais", com as quais demonstra como "a história dos diversos aspectos da língua deixa seus traços no espaço" (BASSETTO, 2001, p. 78).

Com as cinco normas areais definidas por Mateo Bartoli (1873-1946), utilizando dados da geografia linguística, o método complementa o método histórico-comparativo para numerosos vocábulos dos quais não há documentação disponível.

Através da neolinguística ou linguística espacial, abre-se mais uma possibilidade para a datação de uma parcela do léxico, apesar de pouco confiável, dado o grande número de exceções, quando aplicada na prática. Por isto, só deve ser aplicada como complemento do método histórico-comparativo e levando-se em conta as possíveis exceções.

\subsection{Método da teoria das ondas}

Johannes Schmidt (1843-1901) contesta a teoria da árvore genealógica de August Schleicher (1821-1868), que imaginou as línguas como organismos que nascem, crescem e se desenvolvem como qualquer ser vivo e, depois, envelhecem e morrem, sem qualquer intervenção da vontade de seus usuários, de modo que a distribuição das línguas poderia ser visualizada graficamente como uma árvore genealógica.

Schmidt contesta a ideia de que as características das línguas sejam imanentes e transmitidas hereditariamente, mas, pelo contrário, que assimilam características desenvolvidas em centros de influência e transmitidos em ondas, que se cruzam e entrecruzam com frequência.

Visto assim, fica evidente que a doutrina de Schleicher está mais fundamentada no método histórico-comparativo e a de Schmidt, mais na geografia linguística. Isoladamente, esse método seria pouco produtivo nos estudos de filologia românica, mas pode ser 
extremamente útil se for combinado com elementos da geografia linguística, da linguística espacial e de outros métodos (Cf. BASSETTO, 2001, p. 81-83).

\subsection{Métodos afins}

Vários outros métodos existem e podem ser úteis também aos estudos filológicos ou linguístico-filológicos, como a geologia linguística, a estratigrafia linguística, a teoria dos campos linguísticos (de Jost Trier, 1894-1970), a lexicologia social (de Georges Matoré, 1908-1998) e o estruturalismo (de Ferdinand de Saussure, 1857-1913), entre outros, mas não trataremos deles aqui porque seriam menores suas contribuições e porque gostaríamos de dar maior destaque à crítica textual, que é o mais antigo e tradicional método da filologia, constituindo-se no cerne do trabalho filológico em seu sentido mais restrito.

\section{A crítica textual e a ecdótica}

Apesar de terem sido publicados numerosos artigos pelo Círculo Fluminense de Estudos Filológicos e Linguísticos e ser bastante rica a produção brasileira de crítica textual, os livros teóricos sobre este método têm sido bastante escassos e todos eles bem recentes: em 1967, Elementos de Bibliologia, de Antônio Houaiss (ed. fac-similar em 1983); em 1972, Estudos de Crítica Textual, de Emmanuel Pereira Filho; em 1977, Introdução à Ecdótica: crítica textual, de Segismundo Spina (2. ed. em 1994); em 1985, A construção do livro, de Emanuel Araújo (2. ed. em 2008); em 1987, Iniciação em Crítica Textual, de Leodegário A. de Azevedo Filho; em 1998, Ensaios de Linguística, Filologia e Ecdótica, de Leodegário A. de Azevedo Filho; em 2004, Fundamentos da Crítica Textual, de Barbara Spaggiari e Maurizio Perugi, e Base teórica de Crítica Textual, de Leodegário A. de Azevedo Filho; em 2005, Crítica Textual e edição de textos, de José Pereira da Silva e Introdução à Crítica Textual, de César Nardelli Cambraia, além de algumas poucas traduções.

No mesmo ano de 2007, organizamos um pequeno volume de 128 páginas, intitulado Para uma bibliografia brasileira de Crítica Textual, para auxiliar os pesquisadores sobre o tema, disponível em http://www.filologia.org.br/pereira/textos/bibliografia_brasileira.pdf.

Para a melhor orientação deste tópico, seguirei a estrutura do livro de César Nardelli Cambraia (2005), começando por sua definição e sua história, lembrando os tipos e normas de edição e, por fim, uma síntese da metodologia propriamente dita. 


\subsection{O conceito de crítica textual}

Cambraia lembra a brincadeira denominada "telefone sem fio" para demonstrar a realidade fundamental de que a crítica textual é necessária para se reconstituir a "forma genuína dos textos", pois eles sofrem, naturalmente, muitas "modificações ao longo do processo de sua transmissão", sugerindo que os professores da disciplina façam com os seus alunos a referida brincadeira em sala de aula para que saibam que "a cada cópia que se faz de um texto, a constituição deste muda - seja por ato voluntário, seja por ato involuntário de quem o copia" (CAMBRAIA, 2005, p. 1).

Entendendo-se que o texto sofre alterações em sua transmissão, é natural que, quanto mais antigo seja o seu original, maiores as possibilidades de ter havido deteriorização.

Neste caso, tanto podem ocorrer alterações por intervenção (voluntária ou não) dos copistas ou editores, quanto pode haver alterações por desgaste do suporte (como um furo na folha ou até mesmo a perda de algumas delas) ou um borrão etc.

Além disso, é bom estar ciente de que, muitas vezes, o próprio autor modifica parte de seu texto durante seu processo de produção ou difusão, estabelecendo o que se costuma chamar de variantes autorais, o que não é tão raro como se espera. Aliás, é bastante comum serem encontradas variantes dentro de uma mesma edição, pois é possível que, depois de impresso certo número de páginas ou de exemplares, sejam detectados e corrigidos pequenos erros, dando-se continuidade ao trabalho de impressão, como se nada tivesse acontecido.

Em alguns processos mais antigos de reprodução, às vezes ocorria, por exemplo, de se perder, quebrar ou desgastar algum caractere ou tipo e este ser substituído depois que algumas cópias tenham saído com defeito de impressão. Em síntese, os erros ocorrem naturalmente na transmissão de um texto. E é a crítica textual que tem de sanar esse problema.

A "recuperação do patrimônio cultural escrito de uma dada cultura" é a mais importante contribuição da crítica textual, que vai ter "impacto sobre toda atividade que se utiliza do texto escrito como fonte", tais como a literatura, a linguística, a história e várias outras (Cf. CAMBRAIA, 2005, p. 19-21).

Assim como é fundamental para o progresso de outras ciências, a crítica textual depende também de outras como ciências auxiliares, tais como a paleografia, a diplomática, a codicologia, a bibliografia material e a linguística, entre outras.

\subsection{Um pouco de história}


Praticamente, a crítica textual e a filologia surgiram no III século antes de Cristo, a partir da constituição da biblioteca de Alexandria como importante centro de estudos, por ordem de Ptolomeu I (306 a 283 a.C), destacando-se, inicialmente, Zenódoto de Éfeso, Aristófanes de Bizâncio e Aristarco de Samotrácia, além de Apolônio de Rodes e Eratóstenes de Cirene.

Entre os romanos, podem se destacar Marco Terêncio Varrão (116-27 a.C.) e Marco Valério Probo (20-105 d.C.) e, mais tarde, Orígenes (185-253 d.C.) e São Jerônimo (347420), dedicados editores dos livros sagrados do cristianismo.

No século XIX, a crítica textual se organizou como uma ciência moderna a partir dos trabalhos de Karl Lachmann, que sintetizou a nova metodologia, dividida em duas partes: a recensão e a emenda ou correção.

Para a recensão, estabeleceram-se os seguintes critérios, segundo Timpanaro, citado por Cambraia (2005, p. 51-52):

1) o repúdio da vulgata ${ }^{4}$ e a exigência de não se recorrer irregularmente aos códices, mas de os empregar como fundamento da edição;

2) a desconfiança em relação aos códices da época humanista;

3) a reconstrução da história do texto e, particularmente, das relações genealógicas que ocorrerem entre os manuscritos que subsistiram; e

4) a formulação de critérios para determinar mecanicamente, sem se recorrer ao juízo (latim iudicium) do editor, qual, dentre várias lições, remonta ao arquétipo.

O francês Joseph Bédier (1864-1938) apresentou severas críticas ao método lachmaniano, defendendo "o método de se editar um texto com base em um 'bom manuscrito', publicado quase sem retoques e acompanhado de notas que marcam (...) um retorno na direção da técnica dos antigos humanistas" (CAMBRAIA, 2005, p. 52), que também foi criticado por Henri Quentin (1872-1935) em seus Ensaios de Crítica Textual (QUENTIN, 1926).

Por fim, o método lachmanniano foi retificado e aperfeiçoado por Paul Maas (18801964) e Giorgio Pasquali (1885-1952), passando a constituir o que se passou a chamar de neolachmannianismo (Cf. SPAGGIARI; PERUGI, 2004, capítulo 4, p. 60-120).

\footnotetext{
4 Isto é, da forma do texto que passou a ser reproduzida sucessivamente desde as primeiras edições (TIMPANARO, 2002, p. 3). "Sem questionar em nada a exigência científica da integridade do texto, pode-se afirmar, contudo, que a 'vulgata' continua a ser, muitas vezes, em documento nada depreciável do ponto de vista da recepção. Neste domínio, a sua relevância histórica é até superior à de qualquer texto original que, antes de fazer objeto duma edição crítica, nunca estivera ao alcance do público” (SPAGGIARI; PERUGI, 2004, p. 179).
} 
"Embora a crítica textual moderna tenha acabado por se polarizar fundamentalmente entre o método de Lachmann e o de Bédier, a investigação na área não tem cessado desde então e uma extensa e fecunda bibliografia de orientação cada vez mais teórica tem sido publicada", resume Cambraia (2005, p. 53).

Spaggiari e Perugi (2004, p. 52) lembram que Barbi (1938) exorta a "manter as distâncias quer respeito à maneira simplista com que se aplica muitas vezes o lachmannianismo, quer respeito ao ceticismo radical do método bédieriano, que nos faria regressar à mera reprodução de um texto só, aparentemente melhor, corrigido apenas dos erros manifestos".

\subsection{Tipos de edição}

Cambraia classifica as edições quanto à forma de estabelecimento de texto em dois tipos fundamentais: as edições monotestemunhais e as edições politestemunhais.

\subsubsection{As edições monotestemunhais}

a) a edição fac-similar ou mecânica, quase sem interferência do editor, mas, documentalmente, muito importante porque reproduz a fonte com grande fidelidade;

b) a edição diplomática, que consiste na transcrição rigorosamente conservadora de todos os elementos presentes no modelo;

c) a edição paleográfica, semidiplomática, paradiplomática ou diplomáticointerpretativa, que consiste na transcrição da fonte ou modelo com pequenas intervenções, tais como o desenvolvimento de abreviaturas e inserção ou supressão de elementos por conjetura para facilitar a leitura do texto e torná-lo acessível a um público menos especializado e tentar corrigir falhas óbvias no processo de cópia do texto, tais como supressão ou repetição de letras;

d) a edição interpretativa é o tipo mais elaborado de uma edição monotestemunhal, atingindo o grau máximo de mediação admissível, seja com o desenvolvimento de abreviaturas, com a atualização ortográfica, com notas filológicas, linguísticas, históricas e outras que se tornarem convenientes, dependendo do público a que se destine a edição. Até muito recentemente a edição interpretativa era chamada também de edição crítica, apesar de 
não haver a recensão, em que os diversos testemunhos ${ }^{5}$ seriam cotejados para o restabelecimento do texto crítico.

Para exemplificar os quatro tipos de edição monotestemunhal, Cambraia reproduz o fólio 11v da carta de Pero Vaz de Caminha nas páginas 99 a 102 e acrescenta a edição modernizada do mesmo fólio, na página 103, que é aquela em que o editor substitui formas linguísticas da fonte por formas atuais, interferindo no léxico e na gramática do texto.

A edição modernizada não tem valor científico, mas é importante para divulgar documentos importantes sem a rigorosa preocupação com a fidelidade formal ao texto, mas a seu conteúdo semântico.

\subsubsection{As edições politestemunhais}

a) a edição crítica, que se caracteriza pelo confronto de mais de um testemunho no processo de estabelecimento do texto, podendo ser autógrafos ou apógrafos, cujo objetivo é reconstruir a última forma que seu autor lhe havia dado;

b) a edição genética ${ }^{6}$, que também compara os testemunhos, mas somente os autógrafos e/ou idiógrafos, para registrar a evolução teórica e/ou estilística do autor no seu processo criativo, de modo que a edição genética deve apresentar a forma final do texto acompanhada do registro das informações relativas à sua gênese, obtidas nas fontes. Veja-se, como exemplo, a edição de As três Marias, de Raquel de Queiroz, elaborada por Marlene Gomes Mendes (1998).

\subsection{Normas de edição}

As normas ou critérios de edição são diferentes para cada tipo, mas não se devem misturar critérios de edição quando se publica um conjunto de textos, a menos que o objetivo seja demonstrar exatamente essa variedade de tipos de edição.

É preciso que as normas sejam sempre: a) apropriadas ao tipo de edição; b) internamente coerentes; c) explícitas e d) rigorosamente aplicadas.

\footnotetext{
${ }^{5}$ É interessante a proposta de Cambraia para se usar a palavra testemunho em lugar de códice, que se tornou tradicional nos textos teóricos de crítica textual, visto que, na realidade, nem sempre se trata de um códice, mesmo quando a fonte é um manuscrito, além do fato de que o testemunho pode ser uma edição, um datiloscrito ou um digitoscrito.

${ }^{6}$ Segundo Spaggiari e Perugi (2004, p. 204), tomando Silvio Elia como autoridade, a crítica genética "constitui uma repetição desprevenida, além de insciente, do papel desempenhado, nos anos 40 , pela crítica das variantes elaborada como corretivo à estética de Croce". Sobre a "filologia e critica das variantes (genética)", leia um pouco mais em Spaggiari e Perugi (2004, p. 198-229).
} 
Além disso, é indispensável decidir sobre o grau de fidelidade ao modelo, pois uma edição pode ser conservadora ou uniformizadora, dependendo de seu público alvo principal. No primeiro caso, mantêm-se rigorosamente todas as formas do original, sem qualquer atualização, seja ortográfica, seja das abreviaturas ou de qualquer outra natureza. Trata-se, normalmente, de edições destinadas a linguistas e filólogos, que precisam documentar rigorosamente a forma linguística do texto para outros estudos.

\subsubsection{Propostas de normas gerais}

Várias propostas de uniformização das normas de edição de textos antigos já foram realizadas, mas nenhuma delas efetivamente implementada, continuando uma grande diversidade que prejudica a atividade editorial e o diálogo sistemático entre os profissionais de diferentes especialidades que atuam efetivamente na edição de textos.

Nas páginas 128 a 132 da obra citada, Cambraia apresenta propostas rigorosas de transcrição de textos para os diversos tipos de edição monotestemunhais, exceto, naturalmente, para a edição fac-similar ou mecânica.

\subsection{Edição crítica}

Para a edição crítica, as normas são descritas mais detalhadamente, no capítulo 6 do livro de Cambraia, dividido em dois tópicos: estabelecimento do texto crítico e apresentação do texto crítico.

\subsubsection{Estabelecimento do texto crítico}

Para se estabelecer o texto crítico é necessário fazer a recensão e, depois, a reconstituição do texto.

$\mathrm{Na}$ recensão, estudam-se as fontes ou testemunhos, que podem ser fontes de tradição direta ou fontes de tradição indireta, sendo as primeiras constituídas de cópias ou edições do texto propriamente dito e as fontes indiretas podem ser traduções, paráfrases, citações etc.

Naturalmente, para se estudar essas fontes, a primeira tarefa é localizá-las e coletá-las, o que já se pode fazer com muito mais facilidade porque há um número cada vez maior de documentos e edições disponíveis ou disponibilizáveis eletronicamente nas diversas bibliotecas e acervos públicos e particulares. E, mesmo quando não estão disponibilizados, 
podem ser preparados por seus detentores e enviados diretamente para o computador do pesquisador, evitando-se enorme gasto de tempo e dinheiro em viagens e transcrições manuais, como eram feitas há poucas décadas.

Localizados e coletados os testemunhos, parte-se para a colação, que é o cotejo rigoroso das cópias, palavra a palavra, com o registro das variantes, pois é a partir dessas variantes que se poderá fazer a estemática, tarefa extremamente importante em uma edição crítica.

A estemática constitui a fase da recensão que determinará a genealogia dos testemunhos, por comparação baseada nos erros significativos de cada um deles. ${ }^{7}$ Esses erros significativos serão conjuntivos, quando ocorrem em mais de um testemunho, indicando alguma dependência entre eles, ou separativos, quando, ocorrendo em um testemunho, manifesta sua independência em relação aos demais.

Identificados alguns erros, devem ser comparados os lugares comuns em que eles ocorrem e, com isto, é possível estabelecer matematicamente a relação genealógica entre os testemunhos, facilitando a decisão sobre qual deva ser o texto de base.

Depois de estabelecido o estema ou genealogia dos testemunhos de um texto, é importante eliminar os testemunhos comprovadamente copiados de outros. Ou seja: um testemunho que é comprovadamente cópia de outro conhecido deverá ser eliminado porque não trará qualquer contribuição para o estabelecimento do texto, a menos que haja dificuldades como a baixa visibilidade ou se a letra do texto fonte esteja menos legível que o de sua cópia.

Esta subfase de eliminação dos testemunhos copiados é muito importante para a economia de tempo e esforço.

Concluída a recensão, parte-se para a reconstituição do texto, também chamada de emendatio, que pode ser feita com base nos testemunhos ou por conjetura.

A reconstituição por testemunhos é feita com base nos seguintes princípios, regras ou cânones para a seleção de variantes:

a) A lição do maior número de testemunhos é preferível (lectio plurium codicum potior);

b) A lição mais antiga é preferível (lectio antiquior potior);

c) A lição do melhor testemunho é preferível (lectio melioris codicis potior);

\footnotetext{
${ }^{7}$ Erros significativos são aqueles que não poderiam ser corrigidos conjeturalmente pelos próprios copistas por serem erros óbvios. Uma palavra ou expressão sem sentido ou estranha, uma estrutura gramatical que transgrida o padrão linguístico ou estilístico do autor seriam exemplos de erros significativos, porque o autor não escreveria passagens ilógicas ou contrárias ao sentido do texto.
} 
d) A lição mais difícil é preferível (lectio difficilior potior) ${ }^{8}$;

e) A lição mais breve é preferível (lectio brevior potior);

f)A lição que explica a origem de outra é preferível (lectio quae alterius originem explicat potior);

g) A lição que respeita a métrica (res metrica, no texto poético) é preferível;

h) A lição que respeita o estilo da época ou do autor (usus scribendi) é preferível;

i) A lição que respeita o contexto (conformatio textus) é preferível ${ }^{9}$;

A reconstituição por conjetura é aquela que depende exclusivamente do conhecimento e da intuição do editor, sem qualquer amparo incontestável no próprio texto.

Cambraia apresenta-nos um exemplo muito esclarecedor:

Nos testemunhos da lírica trovadoresca galego-portuguesa é muito comum haver lacunas nos refrãos, já que, por ser consabida a estrutura das cantigas, qualquer leitor inferiria que, apesar da lacuna no testemunho, haveria ali a forma completa do refrão. Assim, quando um crítico moderno estabelece o texto de uma dessas cantigas com todos os refrãos plenamente registrados, está, na verdade, reconstituindo-os por conjetura (baseado no conhecimento da estrutura poética das cantigas), já que o registro pleno de todos os refrãos de uma cantiga costuma não estar nos testemunhos (CAMBRAIA, 2005, p. 160).

\subsubsection{Apresentação do texto crítico}

Depois de estabelecido o texto, apesar de não haver consenso em relação a uma forma de apresentação, há certas partes que podem ser consideradas imprescindíveis. Por isto, apresentaremos aqui a sugestão que faz o autor seguido em todo este tópico da crítica textual (CAMBRAIA, 2005, p. 162):

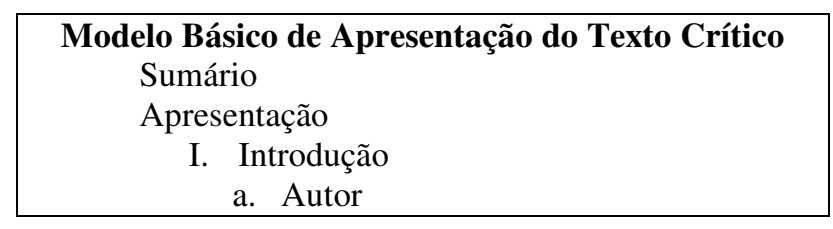

\footnotetext{
${ }^{8}$ Ainda tomando as palavras de Spaggiari e Perugi (2004, p. 94-95), acrescentamos o seguinte importante esclarecimento: "No lachmannianismo tradicional, a 'lectio difficilior' é, junto com o 'usus scribendi', um dos dois princípios com que se pode tentar identificar a lição do original, no caso frequentíssimo de estema bífido, ou, de qualquer maneira, sempre que a 'varia lectio' não possibilitar a aplicação do critério mecânico de escolha. $\mathrm{Na}$ verdade, esquece-se normalmente de precisar que a 'lectio difficilior' é um dos primeiros fenômenos que o editor tem que encarar nos próprios começos do seu trabalho, isto é, na hora de identificar os erros possivelmente conjuntivos ou separativos, indispensáveis à constituição do estema."

${ }^{9}$ No longo estudo que Leodegário A. de Azevedo Filho faz a sua edição fac-similar de Os Lusíadas, de Luís de Camões, centenas de erros apontados se justificam por mera ultracorreção, sobejamente esclarecidos em favor da edição apontada como a editio princeps (CAMÕES, 2008).
} 


\begin{tabular}{|l|}
\hline b. Obra \\
c. Tradição da Obra \\
i. Percurso Histórico \\
ii. Testemunhos \\
iii. Estema \\
iv. Fortuna editoria \\
II. Texto \\
a. Siglas dos testemunhos \\
b. Normas de edição \\
c. Texto e aparato crítico \\
III. Glossário \\
IV. Referências Bibliográficas
\end{tabular}

\section{Conclusões}

Apesar de evidentemente insuficiente para esclarecer profundamente sobre os métodos utilizados pela ciência filológica, tentou-se fazer uma síntese muito restritiva tanto dos métodos aplicados ao sentido amplo que se vem dando à filologia quanto à crítica textual, que é o método incontestavelmente filológico, utilizado para a edição crítica e para a crítica de textos.

Muito mais e melhor se poderia dizer sobre cada um desses métodos e muito ainda se dirá, com certeza.

Estamos aguardando ainda para este ano a publicação do livro de Maximiano de Carvalho e Silva, que deverá trazer interessantes inovações e revisões para a crítica textual no Brasil, onde a profissão de filólogo e de professor de filologia é regulamentada pelo Ministério do Trabalho e Emprego, e incluída no Catálogo Brasileiro de Ocupações, como se pode ver na página http://www.mtecbo.gov.br/cbosite/pages/home.jsf.

Estamos felizes com os progressos dos estudos de crítica textual neste século XXI e lembramos, como mera exemplificação, dois volumes publicados em 2009 com vinte e seis importantes artigos sobre o tema: Lecturas y textos en el siglo XXI: nuevos caminos en la edición textual, organizado por Cristina Castillo Martínez e José Luis Ramírez Luengo, e o número 10/11 da revista Filologia e Linguística Portuguesa, da USP.

Agradecemos a oportunidade de utilizar este livro para fazer a divulgação, mesmo que muito resumidamente, dos métodos da filologia em seu sentido amplo e em seu sentido restrito, e, muito especialmente, ao Prof. Dr. Ricardo Tupiniquim Ramos e à Professora Dra. Patrícia Kátia da Costa Pina, pelo convite e pela tolerância.

\section{Referências bibliográficas:}


ARACIL, Lluís V. Do latim às línguas nacionais: introdução à história social das línguas europeias. Santiago de Compostela: Associação de Amizade Galiza-Portugal, 2004.

AUERBACH, Erich. Introdução aos estudos literários. 2. ed. São Paulo: Cultrix, 1972.

AZEVEDO FILHO, Leodegário A. de. Base teórica de crítica textual. Rio de Janeiro: H, P. Comunicação, 2004.

Ensaios de linguística, filologia e ecdótica. Rio de Janeiro: SBLL/UERJ, 1998.

Iniciação em crítica textual. Rio de Janeiro: Presença; São Paulo: Edusp, 1987.

BARBI, Michele. La nuova filologia e l'edizione dei nostri scrittori da Dante a Manzoni. Firenze: Sansoni, 1938; La lettere, 1994.

BASSETTO, Bruno Fregni. Elementos de filologia românica: história externa das línguas. São Paulo: Editora da Universidade de São Paulo, 2001.

BÉDIER, Joseph. La tradition manuscrite du Lai de L'Ombre: réflexions sur l'art d'éditer les anciens textes. Romania, Paris, t. LIV, anné 57, p. 161-98/321-356, 1928. [Reedição ampliada: Paris: Champion, 1929].

BESSA, José Rogério Fontenele (Coord.). Atlas linguístico do estado do Ceará. Fortaleza: UFC, 2010, 2 vol.

CAMBRAIA, César Nardelli. Introdução à crítica textual. São Paulo: Martins Fontes, 2005.

CAMÕES, Luís de. Os Lusíadas. Rio de Janeiro: Francisco Alves, 2008.

FILOLOGIA e Linguística Portuguesa. Departamento de Letras Clássicas e Vernáculas / Faculdade de Filosofia, Letras e Ciências Humanas / Universidade de São Paulo, vol. 10/11, 2008/2009. São Paulo: FFLCH-USP, 2009.

HOUAISS, Antônio. Elementos de bibliologia. Rio de Janeiro: Instituto Nacional do Livro, 1967, 2 vols.

ILARI, Rodolfo. Linguística românica. São Paulo: Ática, 1992.

IORDAN, Iorgu. Introdução à linguística românica. 2. ed. Lisboa: Fundação Calouste Gulbenkian,1982.

MAAS, Paul. Textkritik. Leipzig: B. G. Teubner, 1927. [2. ed. 1950].

MARTÍNEZ, Cristina Castillo; LUENGO, José Luis Ramírez (Eds.). Lecturas y textos en el siglo XXI: nuevos caminos en la edición textual. Lugo, España: Axac, 2009.

MENDES, Marlene Gomes. Edição crítica em uma perspectiva genética de As três Marias, de Raquel de Queiroz. Niterói, RJ: UFF, 1998. 
PASQUALI, Giorgio. Storia della tradizione e critica del texto. Firenze: Le Monnier, 1934; 2. ed. Firenze: Le Lettere, 1988.

PEREIRA FILHO, Emmanuel. Estudos de crítica textual. Rio de Janeiro: Gernasa, 1972.

Projeto Atlas Linguístico do Brasil.

Disponível em: http://twiki.ufba.br/twiki/bin/view/Alib/WebHome.

QUENTIN, Henri. Essais de critique textuelle (ecdotique). Paris: Auguste Picard, 1926.

SILVA, José Pereira da. Crítica textual e edição de textos. Rio de Janeiro: Edição do Autor, 2005.

SILVA, José Pereira da. (Org.). A edição filológica como se faz hoje. Rio de Janeiro: CiFEFiL, IL-UERJ, ABF e CFCM, Cadernos do CNLF, v. 5, n. 7, 2002.

Crítica textual e edição de textos. Rio de Janeiro: CiFEFiL, 2007. Suplemento da Revista Philologus, Ano 13, n. 37.

Edição de textos e crítica textual. Rio de Janeiro: UERJ-IL, ABF e CFCM, Cadernos do CNLF, v. IV, n. 6, 2000.

Filologia e ecdótica. Rio de Janeiro: CiFEFiL, Cadernos do CNLF, v. 10, n. 9, 2006.

SPAGGIARI, Barbara; PERUGI, Maurizio. Fundamentos da crítica textual. Rio de Janeiro: Lucerna, 2004.

SPINA, Segismundo. Introdução à edótica: crítica textual. São Paulo: Cultrix/Edusp, 1977 [2. ed. rev. e atual. São Paulo: Ars Poetica; Edusp, 1994].

TIMPANARO, Sebastiano. La genesi del metodo del Lachmann. 2. ed. Torino: Liviana, 2002.

THUN, Harald; AQUINO, Almidio; WOLF, Dietrich; SYMEONIDIS, Haralambos. Atlas linguístico Guaraní-Románico. Tomo I: Léxico del cuerpo humano. Kiel, Alemanha: Westensee, 2009 (Dialectologia pluridimensionalis Romanica: 11).

VASCONCELLOS, José Leite de. Lições de filologia portuguesa. 3. ed. Rio de Janeiro: Livros de Portugal, 1959 [4. ed., 1966].

VASCONCELOS, Carolina Michaëllis de. Lições de filologia portuguesa, segundo as preleções feitas aos cursos de 1911/12 e de 1912/13. Seguidas das lições práticas de português arcaico. São Paulo Martins Fontes, s/d.

VIARO, Mário Eduardo. Etimologia. São Paulo: Contexto, 2011.

VIDOS, Benedek Elemér. Manual de linguística românica. Rio de Janeiro: Eduerj, 1996. [2. ed., 2001]. 
The method in Philology

Abstract: : The article is a critical overview on the philological studies, and investigates the question of the method, inseparable from the history of the Romanic Linguistics.

Key words: Philology. Method. Textual criticism. Ecdotic. 